\title{
Employing Laccase-Producing Aspergillus sydowii NYKA 510 as a Cathodic Biocatalyst in Self-Sufficient Lighting Microbial Fuel Cell
}

\author{
Yomna K. Abdallah ${ }^{1}$, Alberto T. Estevez ${ }^{2}$, Diaa El Deen M. Tantawy ${ }^{1}$, Ahmad M. Ibraheem ${ }^{1}$, and Neveen M. \\ Khalil $^{3 *}$ \\ ${ }^{1}$ Interior Design and Furniture Department, Faculty of Applied Arts, Helwan University, Egypt \\ ${ }^{2}$ Biodigital Architecture, Faculty of Architecture, Universidad Internacional de Catalunya UIC, Barcelona, Spain \\ ${ }^{3}$ Botany and Microbiology Department, Faculty of Science, Cairo University, Giza 12613, Egypt
}

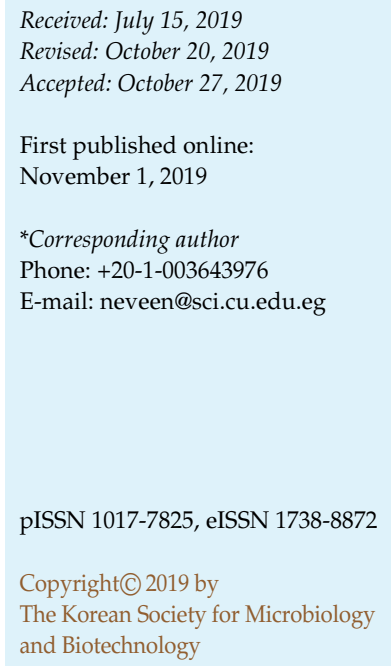

In the present work, we isolated and identified Aspergillus sydowii NYKA 510 as the most potent laccase producer. Its medium constituents were optimized to produce the highest possible amount of laccase, which was after 7 days at $31^{\circ} \mathrm{C}$ and $\mathrm{pH} 5.2$. Banana peel and peptone excelled in inducing laccase production at concentrations of 15.1 and $2.60 \mathrm{~g} / 1$, respectively. Addition of copper sulfate elevated enzyme yield to $145 \%$. The fungus was employed in a microbial fuel cell (MFC). The best performance was obtained at $2000 \Omega$ achieving $0.76 \mathrm{~V}, 380 \mathrm{mAm}^{-2}, 160 \mathrm{mWm}^{-2}$, and $0.4 \mathrm{~W}$. A project to design a self-sufficient lighting unit was implemented by employing a system of 2 sets of 4 MFCs each, connected in series, for electricity generation. A scanning electron microscopy image of A. sydowii NYKA 510 was utilized in algorithmic form generation equations for the design. The mixed patterning and patterned customized mass approach were developed by the authors and chosen for application in the design.

Keywords: Aspergillus sydowii, laccase, microbial fuel cell, self-sufficient lighting design

\section{Introduction}

Microorganisms play a crucial role as biocatalysts in electricity production by employing their natural exoelectrogenic properties in microbial fuel cells (MFCs). Although energy generated from MFCs is relatively low when compared to other fuel cell technologies they can generate electrochemical energy from different types of wastes. They can be applied in small electrical gadgets [1], for instance, Rahimnejad et al. [2] fabricated a stacked MFC as a power source to turn on a digital clock and ten LED lamps. Both devices operated successfully for 2 days.

Compared to unmediated MFCs, those with a mediator would need high concentrations of electron carriers which may be toxic and impractical when considering large-scale electricity generation [3-6]. On the other hand, the air cathode, membrane-less, single-chamber MFC (ACMSCMFC) has several advantages when using the singlechambered MFCs versus the system of two-chambers, such as lower operating cost, increased transfer of mass to the cathode, an overall decrease in reactor volume, and a simplified design [7-9].

Laccases are blue multi-copper oxidases. They can be employed in various applications comprising biofuel cells and biosensors. They are found in fungi, bacteria and plants as well as insects. Fungal laccases are of special interest among these sources. This is due to their ability to break down ligninocellulosic biomass [10,11]. Laccases can catalyze the breakdown of organic compounds while using molecular oxygen as the electron acceptor. When they were purified from fungal sources and immobilized on the cathode surface of an MFC, they increased electricity generation. They served as a biocatalyst on the cathode transferring electrons from the cathode to molecular oxygen $[12,13]$. But the process of purification is laborious and more costly. In addition, the enzymes can be denatured leading to a decrease in their activity [14]. This problem can be overcome by replacing the purified 
immobilized enzyme with laccase-producing whole fungal cells. In recent studies, MFCs have been designed with a laccase-producing fungus on the cathode with high performance in electricity generation $[12,15]$.

This research focused on surveying laccase production by some fungi. The growth conditions of the most potent fungus were optimized for the highest possible production of laccase. This fungus was employed as the biocatalyst in air cathode, membrane-less, single-chamber microbial fuel cells for electricity production. The achieved results were then implemented in a design project based on applying biodigital design procedures in form generation of a selfsufficient lighting unit.

\section{Materials and Methods}

\section{Fungal Strains}

Isolation of fungal strains from agricultural soil inside Cairo University, Giza, Egypt was accomplished according to Johnson et al. [16]. The isolated fungal strains were identified at the species level according to the protocols suggested by Moubasher [17] and Watanabe [18]. Pleurotus ostreatus was kindly provided from Ain Shams University, while instant dry Baker's yeast, Saccharomyces cerevisiae, commercially sold for baking purposes, was purchased. Fungal strains were maintained on potato dextrose agar (PDA) slants and kept at $4^{\circ} \mathrm{C}$.

\section{Laccase Production Survey}

The basal medium was adopted from Olga et al. [19] for screening fungal isolates for laccase production. After inoculation and incubation for 7 days at $30^{\circ} \mathrm{C}$, culture filtrate was obtained and used for measuring extracellular laccase production.

\section{Enzyme Assay}

Guaiacol was utilized as substrate to assay laccase activity according to Das et al. [20].

\section{Molecular Identification of Aspergillus sydowii}

The genomic DNA was obtained through the protocol of a GeneJet Plant Genomic DNA Purification Kit (Thermo) \# K0791 [21]. Internal transcribed spacer (ITS) region of 5.8S rRNA was amplified by the primers ITS1 with sequence $5^{\prime}$ TCC GTA GGT GAA CCT TGC GG 3', and ITS4 with sequence 5'TCC TCC GCT TAT TGA TAT GC 3'. PCR sequencing using traditional Sanger technology and the new 454 technology was utilized for the amplified product at GATC Company (Germany). A strain identifier and an accession number were obtained from GenBank of NCBI database.

\section{Optimizing Growth Conditions of $A$. sydowii NYKA 510}

Growth conditions of $A$. sydowii NYKA 510 on Czapek-Dox broth medium were optimized to reach maximum production of laccase. The physical factors included incubation period, temperature and $\mathrm{pH}$. The chemical factors comprised carbon source, banana peel concentrations, nitrogen source, peptone concentrations and metal ions $(10 \mu \mathrm{M})$. In each tested condition, the optimized medium was inoculated and then incubated under the previous successive treatments.

\section{ACMSC-MFC Performance}

The membrane-less, single-chamber microbial fuel cell (ACMSCMFC) had a volume of $117.25 \mathrm{ml}$ ( $5 \mathrm{~cm}$ diameter, $6 \mathrm{~cm}$ length). The electrode dimensions were $5 \mathrm{~cm} * 5 \mathrm{~cm}$, with an electrode surface area of $25 \mathrm{~cm}^{2}$. The MFC was manufactured with the use of the construction material transparent Perspex (Omega, Egypt). The methods of Cheng et al. [22] and Khater et al. [23] were followed.

Optimized medium constituents were: banana peel $(15.1 \mathrm{~g} / \mathrm{l})$ as carbon source; peptone (2.6 g/l) as nitrogen source; $\mathrm{K}_{2} \mathrm{HPO}_{4}$ ( $(1 \mathrm{~g} / \mathrm{l})$; $\mathrm{MgSO}_{4} .7 \mathrm{H}_{2} \mathrm{O}(0.5 \mathrm{~g} / \mathrm{l}) ; \mathrm{KCl},(0.5 \mathrm{~g} / \mathrm{l})$ and $\mathrm{FeSO}_{4} .7 \mathrm{H}_{2} \mathrm{O}(0.01 \mathrm{~g} / \mathrm{l})$ and additional metal ions of $\mathrm{CuSO}_{4} \cdot 5 \mathrm{H}_{2} \mathrm{O}(10 \mu \mathrm{M})$ at $\mathrm{pH}$ 5.2. In a sterile laminar flow cabinet, ten discs $(1 \mathrm{~cm})$ obtained from a solid pure culture of $A$. sydowii NYKA 510 were used for the inoculation of $100 \mathrm{ml}$ optimized fungal medium in a $250 \mathrm{ml}$ Erlenmeyer flask. It was then incubated for $24 \mathrm{~h}$ at $31^{\circ} \mathrm{C}$. After that, the flask was shaken gently to disperse spores into the liquid medium and finally transferred to the ACMSC-MFC (washed with ethanol $70 \%$ ) through the plugged upper portal using a sterile syringe. This is to guarantee the condensed domination of A. sydowii NYKA 510 and decrease chances of contamination.

\section{MFC Operation}

A multimeter and data acquisition system (SOOER-SD9205A) was used to record the cell potential every $24 \mathrm{~h}$. The MFC operated for 6 days for each cycle of three open circuit cycles. In each cycle, the addition of fresh medium with inoculations of $A$. sydowii NYKA 510 spores was repeated to regenerate MFC function. After stabilization of electricity production, operation of the MFC took place for several closed cycles till the formation of the biofilm. Once a steady state of power and electricity generation was reached, the ACMSC-MFC was discharged and operated under varied, fixed external resistances; 1000,2000 , or $3000 \Omega$.

The current $(\mathrm{I})$, the power $(\mathrm{p})$ and the current density $\left(\mathrm{mAm}^{-2}\right)$ from the function of surface area of anode [24] were calculated. Current density and power density were normalized to the electrode surface area. The method of the power density curve [25] was followed to procure maximum power density and the internal resistance of the MFC.

\section{Design Project}

Design concept. The design process employed a bottom-up strategy through three main phases:

(1) Phase 1: Bio-catalysis experimentation in ACMSC-MFC

A designed model of the MFC was developed by the authors using Rhinoceros 3D modeling software. The 2,000 $\Omega$ external resistance was chosen to give maximum wattage, which achieved 
$0.4 \mathrm{~W}$ in average per cell for $100 \mathrm{~h}$ (4 days). A set of 4 MFC cells were connected in series configuration. A low wattage LED lamp of 0.8 watt (Festoon Base - T3 Bulb (length: 1.625", lumens: 30, weight (lbs): 0.06) [26] was used where a low amount of light is required. Besides its energy efficiency, it lasts up to $25,000 \mathrm{~h}$, it contains no mercury elements and it does not release any hazardous gases. An LED lamp with fixtures and cables was fixed inside a metal case $(8 \mathrm{~cm} \times 8 \mathrm{~cm} \times 2 \mathrm{~cm})$ with a transparent glass face to allow lighting.

(2) Phase 2: ACMSC-MFC physical, chemical and electrical properties

The criteria that will affect the indulging of the cell unit in interior design were considered; cell dimensions, shape and materials, as well as operation conditions. A cell of $10 \mathrm{~cm} \times 10 \mathrm{~cm}$ $\times 10 \mathrm{~cm}$ was used as the MFC case. The cells' cluster outer container made of Perspex glass utilized a natural form of fungal culture in final design appearance, and eased monitoring.

The cell operated under room temperature $\left(25-30^{\circ} \mathrm{C}\right)$, and in aerated conditions according to the air cathode requirements. The MFC was horizontally fixed by screws on a stainless steel holder. The glass container is openable from the front for further maintenance.

(3) Phase 3: Design generation based on biodigital procedures

Scanning electron microscopy (SEM) was conducted for a 5day-old culture and the biofilm of Aspergillus sydowii NYKA 510 formed inside the MFC.

Scanning Electron Microscopy (sample preparation). Biofilm samples were washed three times with water and ethanol $30 \%$ and then dried for $24 \mathrm{~h}$ at $25^{\circ} \mathrm{C}$. The 5-day-old culture samples were dried. Each sample was mounted on stubs with graphite paste, coated with gold and then imaged with a JEOL JSM 5200 SEM.

Form generation and manipulation. The design concept of the self-sufficient lighting unit is based on growth patterns of Aspergillus sydowii NYKA 510, extracted from a mathematicallybased algorithmic analysis of the SEM imagery of the fresh culture. The image was analyzed to 3D points in space using the image sampler tool in Grasshopper + Rhinoceros 3D. This tool converted each spore of the colony into a group of points and points were converted to spheres. This form generation approach allows infinite iterations of resultant patterns and form to be applied in the design. The design application methods developed by the authors in this work are mass customization, patterning and patterned customized mass.

(1) Mixed approach design manipulation (mass customization / pattern)

This design approach was developed specifically for a living organism's behavior in order to achieve a patterned customized mass based on live pattern pixilation in 3 dimensions.

\section{Statistical Analysis}

In each experiment, data given are the mean of triplicate assays. SPSS 20.0 software was employed for the evaluation of standard error (SE) and for regression analysis.

\section{Results}

\section{Isolation and Identification of Fungal Isolates}

Three fungal strains were isolated from soil and identified as Aspergillus niger, Aspergillus sydowii and Penicillium chrysogenum.

\section{Quantitative Screening of Fungal Isolates for Laccase Production}

From the obtained results (Fig. 1), Aspergillus sydowii displayed the highest production $(2.569 \mathrm{U} / \mathrm{ml})$ of laccase. Accordingly, it was chosen for further investigations.

\section{Molecular Identification of Aspergillus sydowii}

The procured nucleotide sequence was deposited at the NCBI GenBank. The fungal isolate was thus identified as Aspergillus sydowii NYKA 510 with accession number MK060010.

\section{Optimization of Some Growth Conditions of Aspergillus sydowii NYKA 510}

Laccase production by A. sydowii NYKA 510 was monitored during the incubation period (Fig. 2A) where it increased gradually up until 7 days $(2.25 \mathrm{U} / \mathrm{ml})$. Fig. 2B demonstrates a significant increase in laccase production corresponding to the increase in $\mathrm{pH}$ until reaching maximum production $(2.40 \mathrm{U} / \mathrm{ml})$ at $\mathrm{pH} 5.2$. The statistical optimum temperature (Fig. 2C) was $31^{\circ} \mathrm{C}$ for maximum laccase activity of $2.45 \mathrm{U} / \mathrm{ml}$. Obviously (Fig. 2D), banana peel induced the highest laccase production $(3.12 \mathrm{U} / \mathrm{ml})$ followed by glucose $(2.8 \mathrm{U} /$ $\mathrm{ml})$. Statistically, increasing the concentration of banana peel up to $15.1 \mathrm{~g} / 1$ led to the highest increase in the amount of laccase to $3.22 \mathrm{U} / \mathrm{ml}$ (Fig. $2 \mathrm{E}$ ). It is clear from Fig. $2 \mathrm{~F}$ that peptone was the most potent laccase inducer $(3.67 \mathrm{U} / \mathrm{ml})$ followed by sodium nitrate $(3.00 \mathrm{U} / \mathrm{ml})$. The gradual increase (Fig. 2G) in peptone concentration led to a

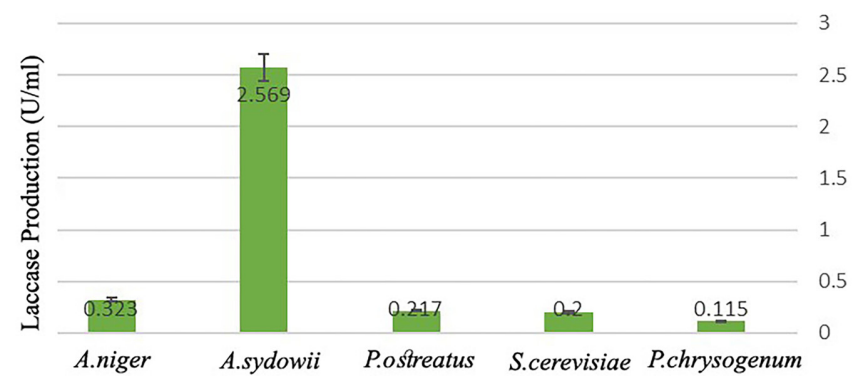

Fig. 1. Laccase production by different fungal isolates. Bars show means. Error bars show mean \pm SE. SE: standard error. 


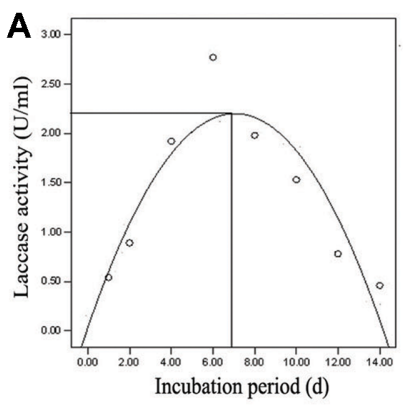

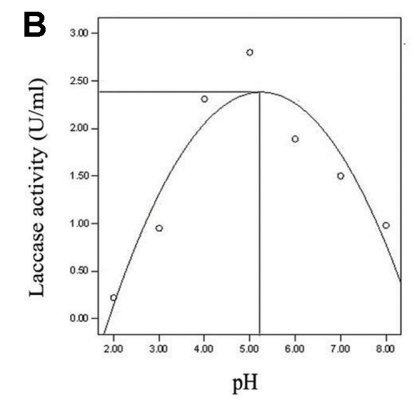

$Y=a x^{2}+b x+c=(-0.211) x^{2}+(2.22) x-3.45 \quad R^{2}=0.868$

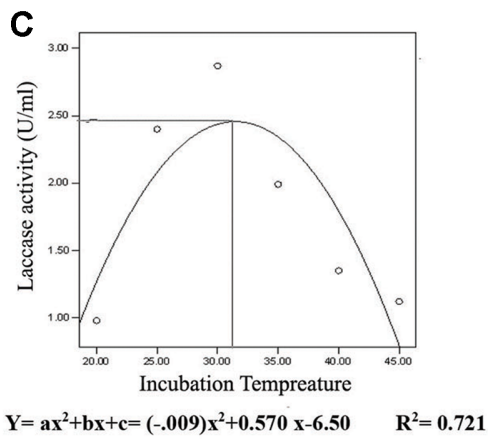

D

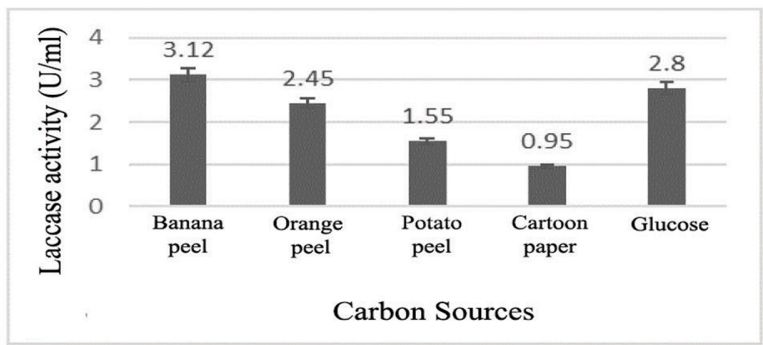

Bars show Means. Error Bars show Mean \pm SE.

$\mathbf{F}$

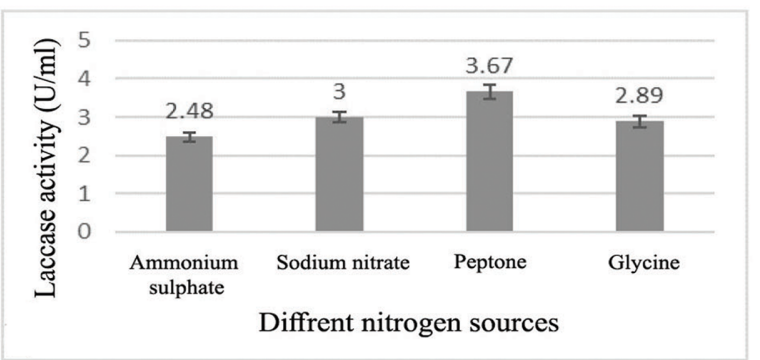

Bars show Means. Error Bars show Mean $\pm \mathrm{SE}$.

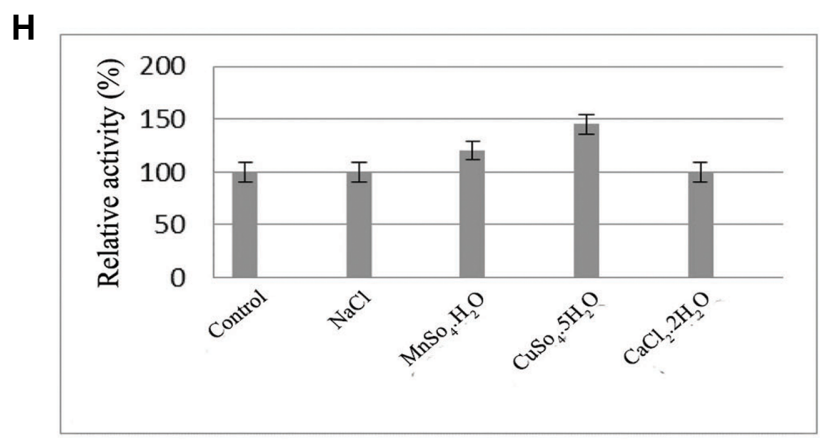

E

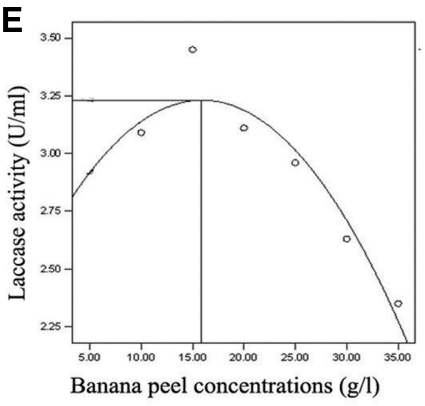

$y=a x^{2}+b x+c=-0.002 x^{2}+0.083 x+2.56 \quad R^{2}=0.891$

G

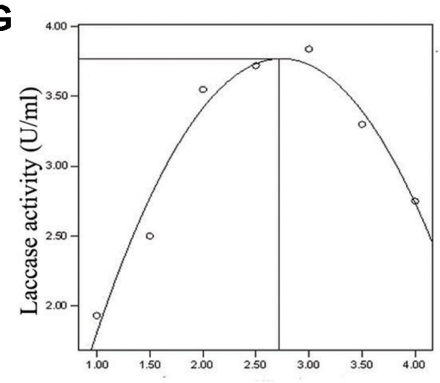

Peptone concentration $(\mathrm{g} / \mathrm{l})$

$y=a x^{2}+b x+c=(-0.63) X^{2}+3.49 X-1.108 \quad R^{2}=0.957$

Bars show Means. Error Bars show Mean $\pm \mathrm{SE}$.

Fig. 2. Optimization of cultural conditions of $A$. sydowii NYKA 510 for maximum laccase production.

Linear regression model fit of different $(\mathbf{A})$ incubation periods, $(\mathbf{B}) \mathrm{pH},(\mathbf{C})$ incubation temperatures, (E) banana peel concentrations or $(\mathbf{G})$ peptone concentrations, as a function of laccase production. Effect of different (D) carbon sources, (F) nitrogen sources or (H) metal ions on laccase production. 

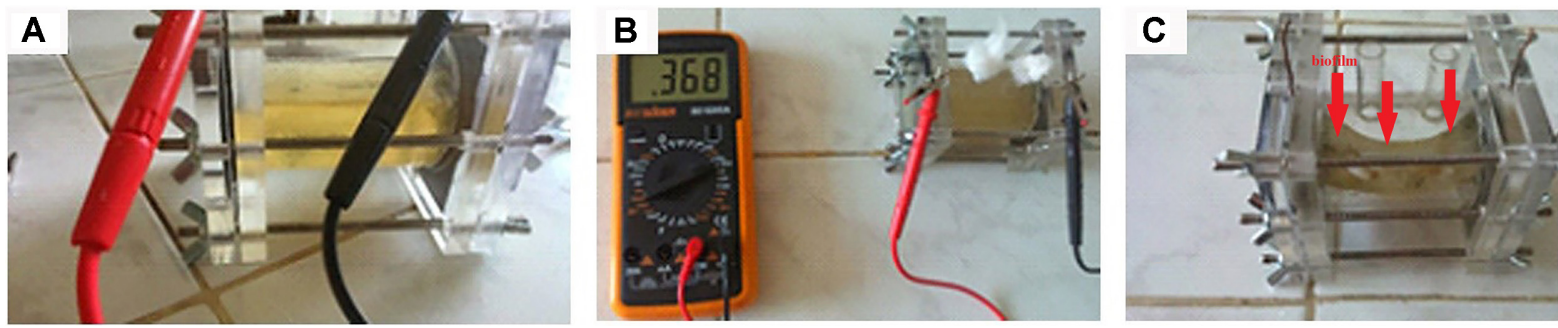

Fig. 3. Microbial fuel cell in (A) fed-batch mode, (B) opencircuit voltage configuration and (C) Aspergillus sydowii NYKA 510 biofilm formation.

concomitant increase in the amount of laccase enzyme with maximum activity of $3.70 \mathrm{U} / \mathrm{ml}$ at $2.60 \mathrm{~g} / 1$. The highest significant promoter effect (145\%) for the tested metal ions was due to $\mathrm{CuSO}_{4} \cdot 5 \mathrm{H}_{2} \mathrm{O}$ addition (Fig. $2 \mathrm{H}$ ).

\section{ACMSC-MFC Operation \& Performance}

Figs. 3A-3C show the ACMSC-MFC operating with Asperigillus sydowii NYKA 510 in fed-batch mode. The fungal biofilm formed between anode and cathode in the MFC is also shown.

Performance over three open circuit cycles was recorded at zero current and unlimited resistance. Fig. 4A reveals that in the open-circuit voltage (OCV), a rapid increase was noticed to values from $0.47 \mathrm{~V}$ to $0.54 \mathrm{~V}$ at the initial inoculation (first $24 \mathrm{~h}$ ). The OCV reached a steady value of approximately $0.58 \mathrm{~V}$ after $50 \mathrm{~h}$ and continued to rise through the following $100 \mathrm{~h}$, then reached maximum voltage of $0.765 \mathrm{~V}$ MFC after $150 \mathrm{~h}$ (6 days). The cell was then recharged with freshly inoculated media recording $0.65 \mathrm{~V}$ in the following $50 \mathrm{~h}(200 \mathrm{~h})$ (8th day). OCV continued to rise again to $0.75 \mathrm{~V}$ up till $300 \mathrm{~h}\left(12^{\text {th }}\right.$ day), as the fresh spores oxidized the carbon source in the fresh medium.

The ACMSC-MFC was discharged and then operated under the effect of fixed loads. As observed in Figs. 4B-4D, the potential, current density as well as power density show the same performance. There was a slow increase in output voltage during first $100 \mathrm{~h}$, and then there was a significant increase in the following $50 \mathrm{~h}$. Maximum voltage $(0.82 \mathrm{~V})$ occurred at external load $3000 \Omega$ which matched a current density of $160 \mathrm{~mA} \mathrm{~m}^{-2}$ and a power density of $80 \mathrm{mWm}^{-2}$ after $150 \mathrm{~h}$ (approximately 6 days). The voltage value of $0.76 \mathrm{~V}$ was achieved at external load $2000 \Omega$ that matched $380 \mathrm{mAm}^{-2}$ current density and $160 \mathrm{mWm}^{-2}$ power density, which is the highest efficiency recorded in this study. The MFC maintained the same performance for the following $100 \mathrm{~h}$ (4days) with minor fluctuations in the first $24 \mathrm{~h}$ after recharging each cycle.
From the polarization curve (Fig. 4E), there was an increase in the power density to its maximum value against the current density then there was a sharp decrease. From Ohm's law, at the maximum power density, the external load is equal to the MFC internal load. Considering the slope of the plot of voltage against current, the internal resistance was determined to be $32 \Omega$ of standard.

A set of four microbial fuel cells connected in series produced $1.5 \mathrm{~W}$ amd was sufficient for lighting a 0.8 watt LED light bulb for $100 \mathrm{~h}$ (4 days).

\section{Design Project}

A designed ACMSC-MFC modeled by the authors using Rhinoceroses 3D modeling software is shown in Fig. 5A. The MFC is loaded with optimized fungal growth medium. It is in closed circuit configuration with external load. Fig. 5B shows a lighting unit design composed of 2 sets of 4 MFCs connected in series and two 0.8 watt LED lamps. In Fig. 5C, there are two sets of MFCs connected in series, each set composed of 4 cells. This is to light two $0.8 \mathrm{~W}$ LED light bulbs. Fixtures and cables are adjusted inside a metal case of $(8 \mathrm{~cm} \times 8 \mathrm{~cm} \times 2 \mathrm{~cm})$ for each bulb. The figure also shows $5 \mathrm{~cm}$ maneuver margins for maintenance and recharging with freshly inoculated media every $150 \mathrm{~h}$ (6 days).

Scanning electron microscopy. The SEM analysis of A. sydowii NYKA 510 culture is shown in Figs. 6A-6C. The fungus appears as mycelium with conidiophores bearing vesicles. Phialides radiate from these vesicles, which carry conidia (spores). The SEM image of fungal biofilm formed at the MFC (Fig. 6D) shows a tangled web of mycelium and conidiophores.

Form generation \& manipulation. The SEM image in Fig. 6A was utilized in this section. The images in Figs. 7A7C show the 3D points that were employed in the algorithmic form generation equations in the present design concept (designed by the authors). 
A

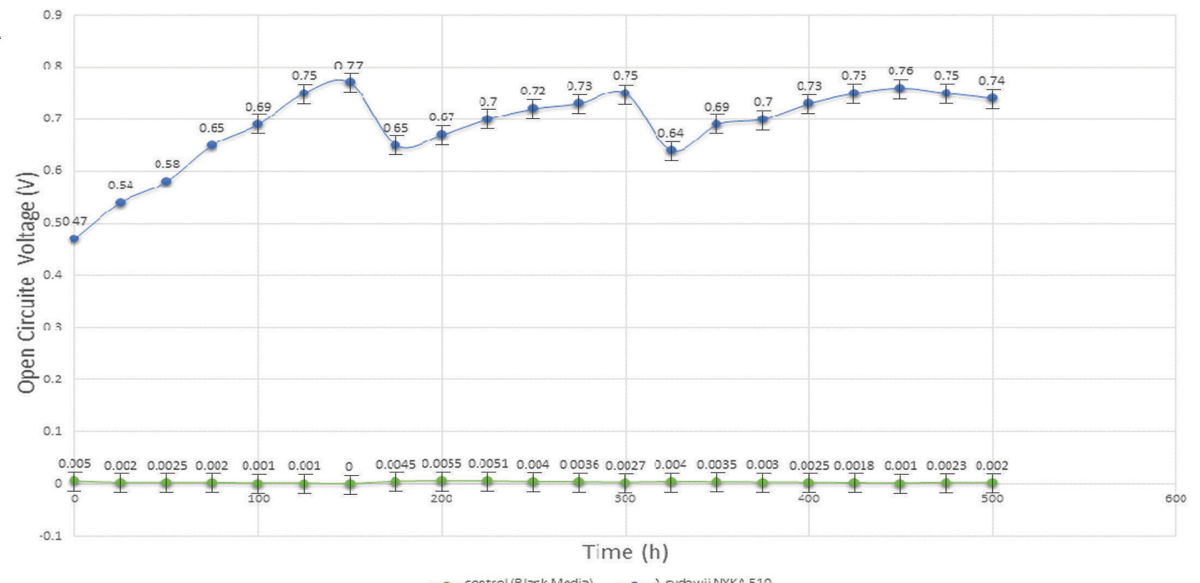

B

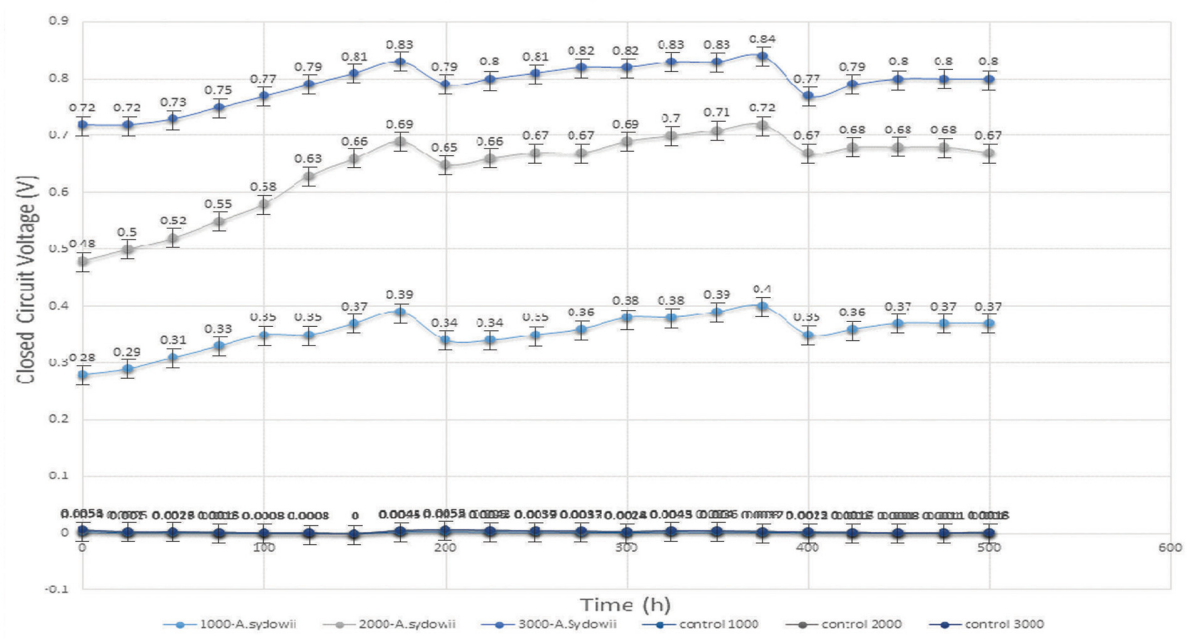

C

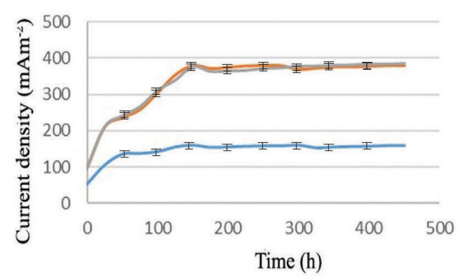

E

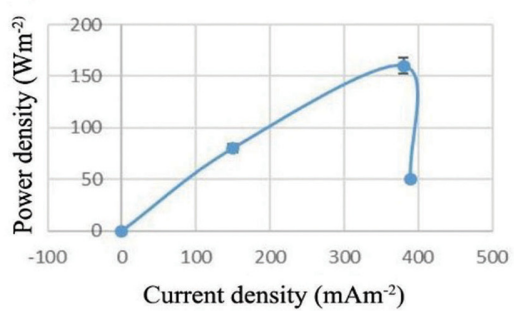

D

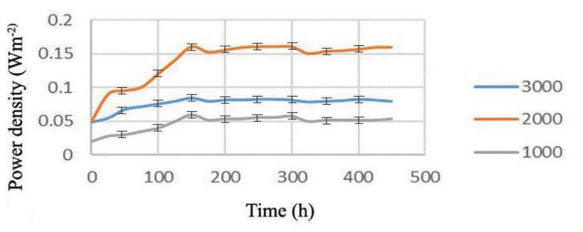

F

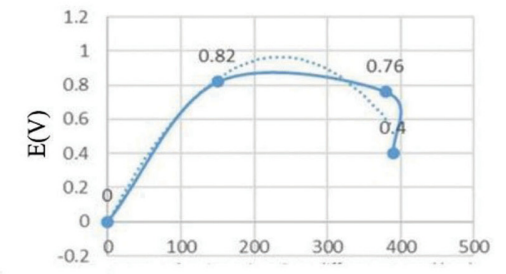

Current density $\left(\mathrm{mAm}^{-2}\right)$ at diffrent external loads

Fig. 4. Performance of ACMSC-MFC operating with A. sydowii NYKA 510 as a biocatalyst.

(A) Performance in open circuit for 3 cycles. Effect of varied resistances, 1000, 2000, or $3000 \Omega$, on voltage production (B), current density production (C) or power density production (D). Polarization curve as a factor of current density against potential (E). Power curve (F).

The three main design application methods developed by the authors were; 1) Mass customization; by further algorithmic processing for resulting forms through scaling, randomization, animation and collision, 2) Patterning: using aggregation through tessellation. In this method, the resulting form is being capsulated as a tile for repetition, 


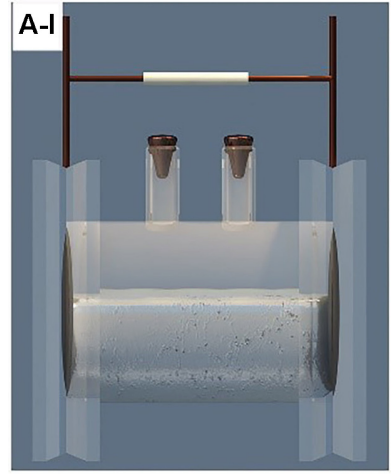

B
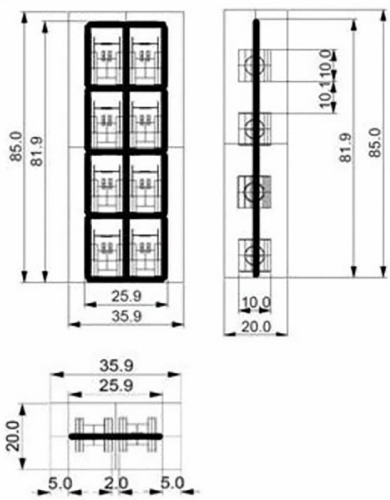

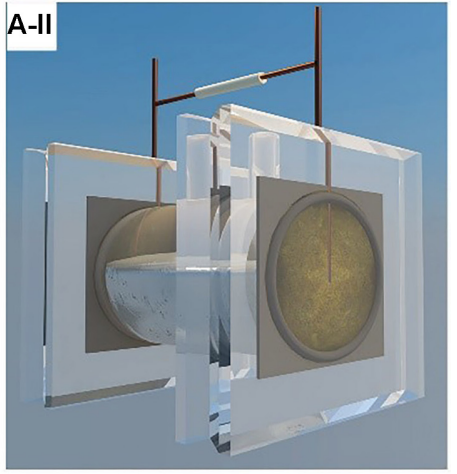

C

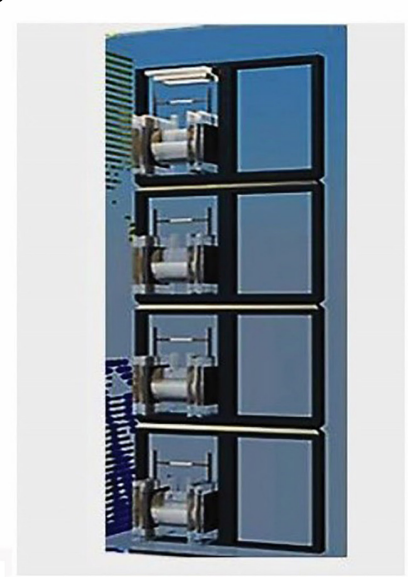

Fig. 5. Lighting unit design utilizing ACMSC-MFC with $A$. sydowii NYKA 510.

Two different views of an ACMSC-MFC modeled by authors (AI and AII). Front elevation of cells fixed on stainless steel frame, side view and plan view, respectively (B). Cells fixed on stainless steel frame (C).

and 3) Patterned customized mass: a mixed approach of the aforementioned methods, based on manipulating patterns through overlapping and transition. This method was applied in the design model, through employing transparency and overlapping the two asymmetrical parts of a simulated

SEM image in the longitudinal axis, to achieve different views along the 360-degree angle of rotation around the $z$ axis.

Fig. 8A represents the mixed approach of patterned customized mass method, showing different forms along a longitudinal axis. Silicone rubber spheres are distributed on the 4 surfaces, fixed on the perforated circles on the glass with the same distribution negative \& positive joint, fixed by the groove on the diameter of the silicone rubber spheres.

The color scheme was defined according to Aspergillus sydowii NYKA 510 culture colors (light olive green to light greenish blue) combined with (blue shades ) to confuse the final design appearance between pattern and real organism (fungus). Fig. 8B shows the lighted unit by the power of MFCs from different views. It also shows pattern overlapping and transition by employing the glass container transparency; to achieve various deferent views around 360 degrees of rotation. The glass container also engages the MFCs with fungal cultures in the final design form to couple the appearance of the growth pattern applied in design and the real growth of Aspergillus sydowii NYKA 510 inside the MFCs.

\section{Discussion}

This work aimed to optimize growth conditions of a nonpathogenic fungal strain, which is capable of producing laccase. This fungal strain was to be employed as a biocatalyst in an air cathode, membrane-less, singlechamber microbial fuel cell (MFC). This MFC would be an electrical self-sufficient system, which would be embedded in interior design elements. Accordingly, this study focused on achieving the most available, easiest, fastest and safest methods for A. sydowii NYKA 510 (the biocatalyst) cultivation media, while balancing these parameters with
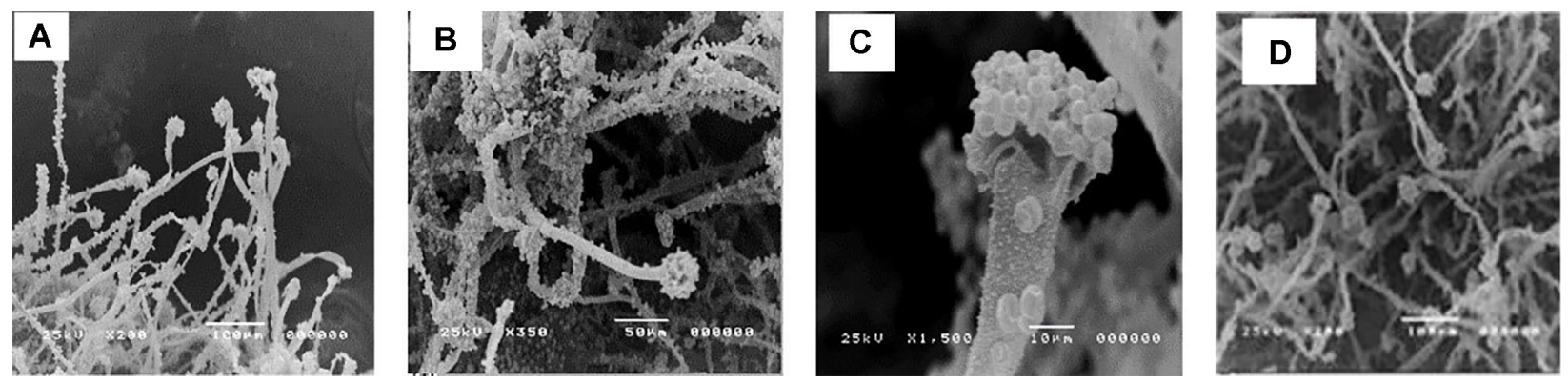

Fig. 6. Typical appearance of Aspergillus sydowii NYKA 510 growth culture at different magnifications $(\mathbf{A}, \times 200 ; \mathbf{B}, \times 350 ; \mathbf{C}, \times 1,500)$ and biofilm formed at MFC (D). 

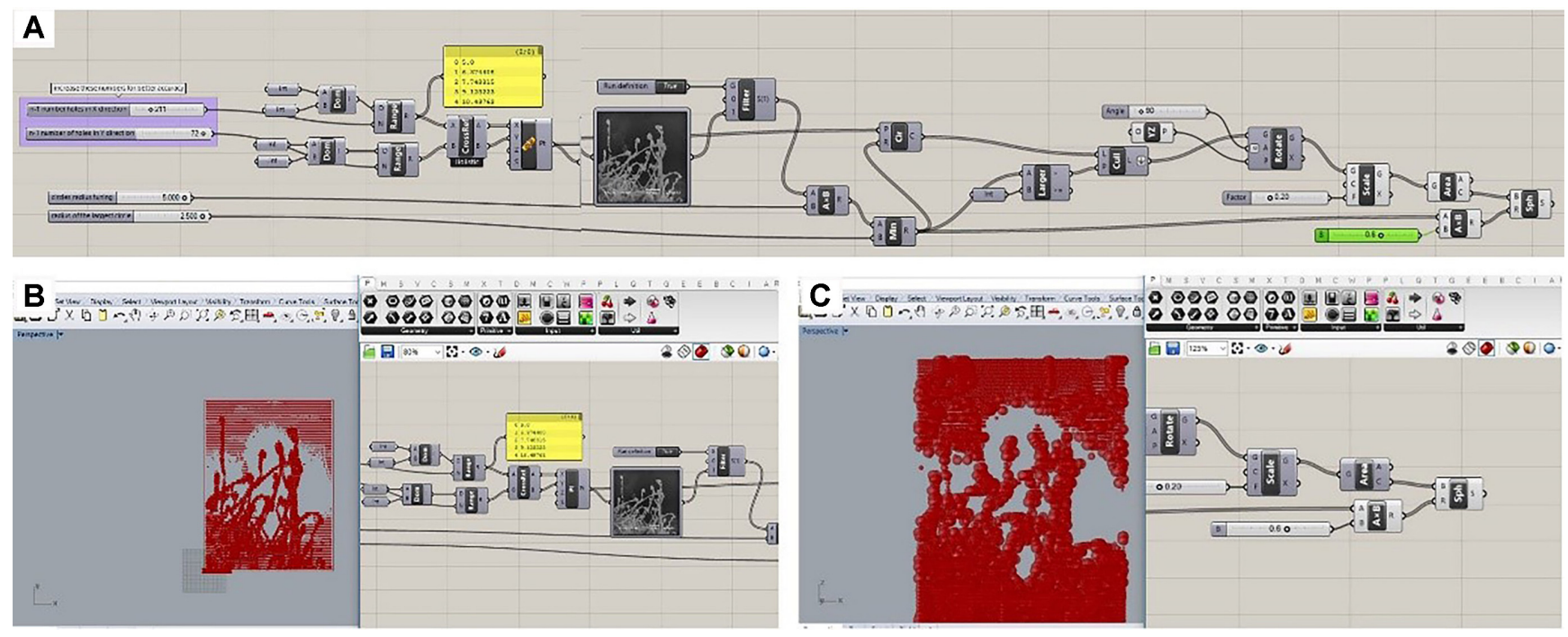

Fig. 7. Aggregation pattern algorithmic analysis and form generation equation (A). First (B) and second (C) steps in form generation development.

the highest amount of laccase activity. In this work, MFC voltage generation is due to the activity of fungal cell oxidoreductase enzymes, e.g. laccase. Previous studies mentioned the role of laccase in enhancing electricity production in MFCs [12]. Here, laccase was used as an indicator of oxidation-reduction activity of fungal cells. Thus, the voltage generation in this work is due to activity of oxidoreductase enzymes produced by fungal cells.

Laccases mediate the oxidation of different phenolic compounds, aromatic amines and a range of other nonphenolic compounds [27]. They catalyze oxygen reduction to water accompanied with one electron oxidation of various substrates. This causes the formation of an oxygencentered free radical [28, 29].

Laccases are particularly abundant in many fungi [29]. Fungal laccases exhibit higher redox potential when compared to plants or bacterial laccases [27]. Laccase was reported from some soil fungal ascomycete species belonging to genus Aspergillus. Genus Aspergillus constitutes a group of filamentous fungi, which are important in wide biotechnological applications in industrial production of enzymes and chemicals [31].

In the present work, selection of tested strains was according to availability, safety, and sustainability. Laccase production was surveyed among the fungal species Aspergillus niger, A. sydowii, Pleurotus ostreatus, Saccharomyces cerevisiae and Penicillium chrysogenum. Aspergillus sydowii achieved the highest laccase production. Cong et al. [32] previously recorded A. sydowii MS-19 to produce oxidoreductases.
Sequences annotated as laccase and peroxidase were obtained sharing similar structures with manganese peroxidase and lignin peroxidase.

Methods, including optimization of media, were followed to render laccases available for domestic applications with reduced cost. Temperature and $\mathrm{pH}$ are key factors in metabolic activity of the microbial cell and enzyme production [28]. Various reports demonstrate that fungal laccases are active at lower $\mathrm{pH}$ values $(3-5)[33,28]$. This supports the results obtained in the current study where maximum laccase production by A. sydowii NYKA 510 occurred at $\mathrm{pH}$ 5.2. Pointing et al. [34] mentioned that optimum range of temperature for laccase production is approximately from $25^{\circ} \mathrm{C}$ to $30^{\circ} \mathrm{C}$. This is concomitant with the results reached in this work where the highest laccase production was achieved at $31^{\circ} \mathrm{C}$. This is also supported by results obtained by Ghosh et al. [28] for the effect of initial culture $\mathrm{pH}$ and temperature on growth of A. flavus PUF 5 where maximum laccase production took place at $\mathrm{pH} 5$ and $30^{\circ} \mathrm{C}$ after 14 days of incubation. In this work, A. sydowii NYKA 510 showed highest laccase production after 7 days.

Carbon and nitrogen sources and concentrations as well as concentration of microelements can influence laccase production $[27,35]$. In the current work, alternative carbon sources from wastes were used to raise laccase production and to add ecological value to the domestically used MFC system. The different residues examined included banana peel, orange peel, potato peel, and carton paper. These are some of the most available and affordable waste products 

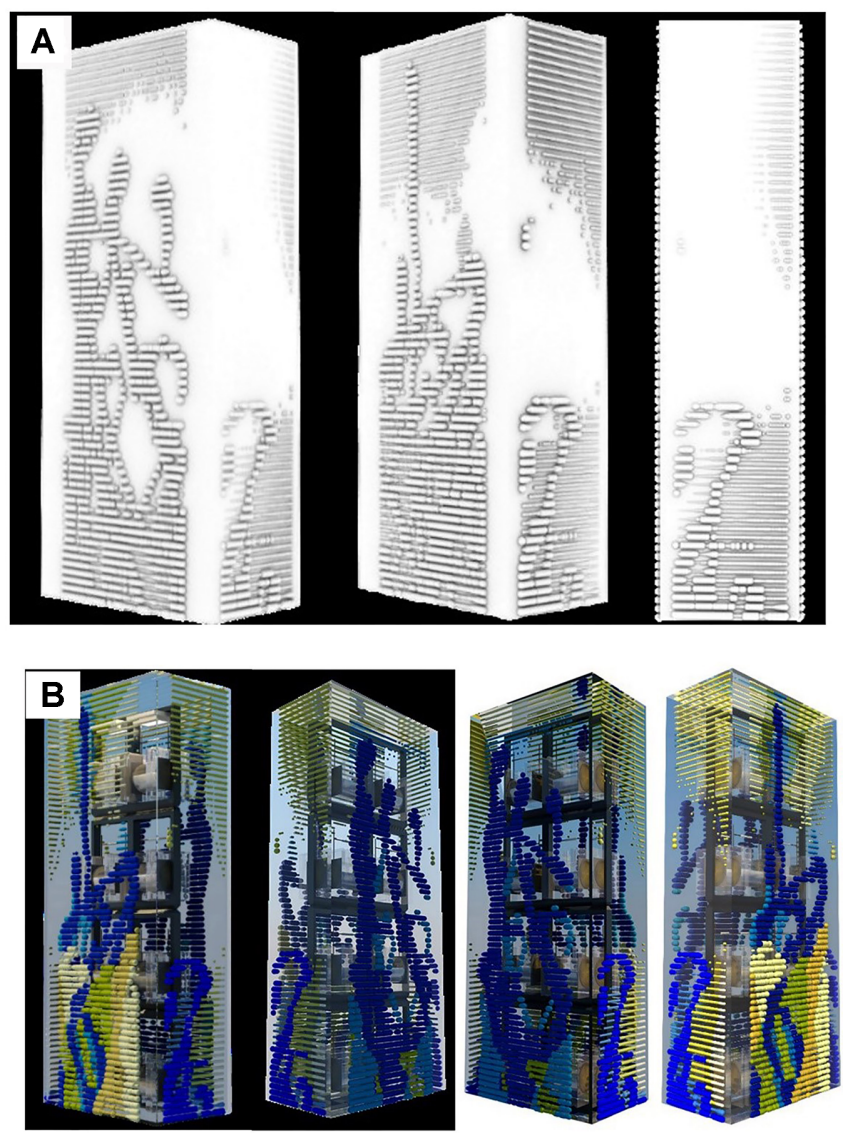

Fig. 8. Mixed approach of patterned customized mass method for a lighting unit design utilizing ACMSC-MFC system.

(A) Patterned customized mass method: showing different forms along longitudinal axis. (B) The final design of a self-sufficient lighting unit powered by ACMSC-MFC from different views, designed by authors using Rhinoceros 3D+grasshopper.

due to domestic use. Maximum laccase activity was achieved with banana peel.

Disposal of bulk amounts of banana peel is of significant importance for fruit-processing industries. In addition, banana fruit is among the most highly used crops in the world accounting for $40 \%$ of the total world trade of fruits and their products. Banana peel is a good substrate for fungal consumption in terms of adherence and penetration due to its porous structure. The peel is highly rich in carbohydrates, ascorbic acid, and potassium [36].

In the current work, the optimum concentration of banana peel was $15.1 \mathrm{~g} / 1$ achieving the highest laccase production, after which the activity deceased. Brijwani et al. [27] stated that higher concentrations of carbon can cause inhibition of the production of laccase by different fungal strains.
Maximum laccase production was achieved in the present study by A. sydowii NYKA 510 using $2.60 \mathrm{~g} / 1$ peptone. These results are congruent with the results obtained by Ghosh et al. [28]. Sources of nitrogen as well as their concentrations are as significant nutritional factors as the sources of carbon, since they regulate production of laccase [37].

In this work, utilizing $10 \mu \mathrm{M} \mathrm{CuSo}{ }_{4} \cdot 5 \mathrm{H}_{2} \mathrm{O}$ recorded significant enhancement in laccase production $(145 \%)$. These results are supported by a previous report [38] where $2 \mathrm{mM} \mathrm{CuSO}_{4} 5 \mathrm{H}_{2} \mathrm{O}$ addition caused a marked increase in production of laccase.

The biocatalyst $A$. sydowii NYKA 510 and its optimized culture conditions, reached in the present study, were utilized in the MFC to generate a stable current [39, 40]. In submerged cultivation, microorganisms grow in liquid medium containing nutrients through aerobic conditions. Wastes can be used as a cheap source of carbon, nitrogen, mineral ions, and other compounds to induce production of enzymes. The authors adopted this type of cultivation applied in the fed-batch mode in the MFC. This technique causes excessive growth of mycelium, which operates a required function in MFC of forming biofilm between the anode and cathode as the fungal spores are dispersed freely and evenly in media. This is essential for current boosting inside the MFC $[28,35]$.

MFC performance is affected by operational factors including substrate nature and concentration, temperature, the microorganism, cathode and anode chamber alkalinity, residence time and external resistance as well as design factors including the materials used in the cathode and anode, and MFC architecture [2]. Two parameters can limit the generation of current in the MFC; rate of oxidization of the substrate by the microorganism and electron transfer rate to surface of the electrode [24]. Rate of oxidation of the substrate depends on substrate concentration, which is usually considered as a reaction of the first order. However, parameters such as transfer of mass and thickness of the biofilm layer can cause suppression in generation of power [41]. The purpose of developing an air-cathode singlechamber MFC with no membrane was to increase transfer of mass to the cathode, decrease operation cost, and decrease volume and design of the reactor. Removing the proton exchange membrane (PEM) increases power output, and substantially decreases the cost of the materials, hence enhancing the MFC sustainability [42]. Oxygen was chosen as an oxidant in the cathode due to the fact that it is available and has an environment-friendly reduction product i.e. water. Application of platinum as an inducer 
was to improve the oxygen reduction rate in the cathode chamber [43].

In this work, the air cathode single-chamber MFC catalyzes the conversion of carbon source into electricity by transferring electrons to the circuit by employing oxidoreductase enzymes secreted by fungal cells. The basic reactions are presented below [44]:

Anodic reaction: $\mathrm{C}_{6} \mathrm{H}_{12} \mathrm{O}_{6}+6 \mathrm{H}_{2} \mathrm{O} \rightarrow 6 \mathrm{CO}_{2}+24 \mathrm{H}^{+}+24 \mathrm{e}^{-}$

Cathodic reaction: $6 \mathrm{O}_{2}+24 \mathrm{e}^{-}+24 \mathrm{H}^{+} \rightarrow 12 \mathrm{H}_{2} \mathrm{O}$

The MFC, in this work, was operated in open-circuit configuration for three successive cycles; each cycle lasted for $150 \mathrm{~h}$ (6 days). This was targeted to produce maximum power output to be applied in an electrical device that depends on stable current. After that, the cell operated under different external loads for 3 cycles each. A preliminary study was conducted by the authors using a wide range of resistors; $5,10,50,100,500,1000,2000$, or $3000 \mathrm{ohms}$. The best performance of the MFC was registered under 1000, 2000, or 3000 ohms, thus these levels were shown in the MFC performance study diagrams.

The maximum open-circuit voltage $(\mathrm{OCV})$ was $0.77 \mathrm{~V}$, with stable current density of $380 \mathrm{mAm}^{-2}$ and a power density of $160 \mathrm{mWm}^{-2}$ was achieved at $2000 \Omega$ external load, after $150 \mathrm{~h}$ (6 days) of incubation, and lasting for $100 \mathrm{~h}$ (4 days) with minor fluctuations due to recharging. This production time is in accordance with laccase production achieved by Aspergillus sydowii NYKA 510 in this study. This maintenance of constant electrical performance is due to the formed biofilm inside the MFC. This is supported by Khater et al. [23] results achieving $0.79 \mathrm{~V}$ OCV and a stable current density of $354 \mathrm{mAm}^{-2}$, using acetate feed ACSCMMFC. The results were also congruent with Lai et al. [7] where a maximum open-circuit voltage of $821 \mathrm{mV}$ and a maximum current density of $330 \mathrm{mAm}^{2}$ were at external load of $1000 \Omega$.

In this work, the authors aimed to employ an MFC as an application for providing bio-electrochemical energy for simple electric gadgets, mainly lighting units. The MFC device and technology are presented to the community of designers, which aren't particularly oriented about this technology. Accordingly, to elucidate the potential use of MFC, the MFC electrical current data output (MFC voltage production and current density) which is dependent on the used resistors were conducted first then followed by the study of polarization tests.

In the current work, there was a directly proportional relationship between potential and resistance, while in case of current density, it was an inversely proportional relation. As supposed by Ohm's low, higher resistance leads to lower generated current. The maximum voltage peak value at $3000 \Omega$ was slightly higher than that in case of $2000 \Omega$ and the voltage peak at 2000 was higher than that in case of $1000 \Omega$. The maximum current density value at $1000 \Omega$ is slightly higher than at $2000 \Omega$ and $2000 \Omega$ is higher than in case of $3000 \Omega$. Comparing potential and current density values between the three tested external loads, the $2000 \Omega$ achieved the best performance. The same is true in the case of power density values, where maximum power density was achieved by $2000 \Omega$, which proves the best MFC performance under $2000 \Omega$.

The results reached in the current study employed the simplest MFC architecture, without the use of mediators or inducers that may be toxic or polluting, while at the same time reducing total cost of MFC and committing to safety criteria for domestic use (home, office). The configuration of a set of four MFCs connected in series achieved 1.5 watts after $150 \mathrm{~h}$ (6 days), and the reading remained almost the same for the following $100 \mathrm{~h}$ (4 days) implying the need of recharging the cell with substrate every 4 days. Two sets of 4 MFCs, each connected in series, were then employed in the design of a self-sufficient lighting unit. This design process followed a bottom-up methodology in coupling function \& form concerning design criteria as cell dimensions, shape and materials, as well as operation conditions.

The MFC was defined on horizontal configuration to maintain stability for electrochemical reaction to occur and prohibit leakage of the inner solution of the MFC. For safety, the set of cells is placed inside a glass cuboid container giving the design its final form and keeping cells from usage accidents.

The design concept was a mathematical basis of growth behavior patterns of Aspergillus sydowii NYKA510 extracted from the algorithmic analysis of its SEM imagery and translating this into $3 \mathrm{D}$ points that were the basis for various 3D form generation and manipulation approaches. This allows infinite iterations of resultant patterns and form to be applied. The resulting patterns were employed in the unit's design. The patterns are porous allowing moderate transparency in order to indulge MFC living components as a part of the design aesthetics, and to maintain ventilation (aerated cathode) of MFC operation.

Application followed three main methods developed by the authors; either as a mass customized unit, as a pattern, or as 
a mixed approach. In the case of mass customization method or the (spatial configuration), the self-sufficient device would be a piece of furniture that generates electricity for lighting. It simplifies maintenance and manipulation. The resulting forms in this method are unexpected and have infinite iterations; they allow for 3D installation in both interior or exterior space (pavilions, benches, etc.). The second method is patterning method or the 2D configuration where the device is a tessellated cluster that could be employed as panels for wall cladding or as standalone partitions. It implies further processing for defining panel relation, electrical connections, estimated resultant power according to panel number and required total power, as well as maintenance. In addition to maneuverability considerations (safety), this method can still provide 3D form design manipulation through controlling tessellation orientation and relation to each other including intersection, juxtaposition and separation. It could be applied to walls and partitions, as interior design elements. The third method, which is mass customized pattern, was applied in this study in the design of the proposed self-sufficient lighting unit. This is based on manipulating patterns via overlapping and transition, through employing transparency and overlapping the two asymmetrical parts of a simulated SEM image in the longitudinal axes. This achieves different views along the 360-degree angle of rotation around the $z$ axis, and engaging the fungal cultures appearance inside the MFC in the final design form. This was emphasized by the chosen color scheme of light olive green to greenish light blue, which is the typical color of Aspergillus sydowii NYKA 510 culture. This application method is a cellular automaton approach including three levels of mimicking, simulation and programming. It can be applied in furniture and small-sized installations.

This research focused on surveying laccase production by some fungi. The growth conditions of the most potent fungus, Aspergillus sydowii NYKA 510, were optimized for the highest production of laccase. This fungus was employed as the biocatalyst in an air cathode, membraneless, single-chamber microbial fuel cell for electricity production. The novelty of this work is that the results reached were implemented in an interior design based on applying biodigital design procedures in form generation of a self-sufficient lighting unit.

\section{Conflict of Interest}

The authors have no financial conflicts of interest to declare.

\section{References}

1. Rahimnejad M, Adhami A, Darvari S, Zirepour A, Oh SE. 2015. Microbial fuel cell as new technology for bioelectricity generation: a review. Alexandria Eng. J. 54: 745-756.

2. Rahimnejad M, Ghoreyshi A, Najafpour G, Jafary T. 2011. Power generation from organic substrate in batch and continuous flow microbial fuel cell operations. Appl. Energy 88: 3999-4004.

3. Santoro C, Arbizzani C, Erable B, Ieropoulos I. 2017. Microbial fuel cells: from fundamentals to applications. A review. J. Power Sources 356: 225-244.

4. Liu H, Logan BE. 2004. Electricity generation using an aircathode single chamber microbial fuel cell in the presence and absence of a proton exchange membrane. Environ. Sci Technol. 38: 4040-4046.

5. Rahimnejad M, Mokhtarian N, Najafpour GD, Ramli W, Wan Daud, Ghoreyshi AA, 2009. Low voltage power generation in a biofuel cell using anaerobic cultures. World Appl. Sci. J. 6: 1585-1588.

6. Najafpour G, Rahimnejad M, Ghoreshi A, 2011. The enhancement of a microbial fuel cell for electrical output using mediators and oxidizing agents. Energy Source 33: 2239-2248.

7. Lai CY, Wu CH, Meng CT, Lin CW. 2017. Decolorization of azo dye and generation of electricity by microbial fuel cell with laccase-producing white-rot fungus on cathode. Appl. Energy 188: 392-398.

8. Chen GW, Choi SJ, Lee TH, Lee GY, Cha JH, Kim CW. 2008. Application of biocathode in microbial fuel cells: cell performance and microbial community. Appl. Microbiol. Biotechnol. 79: 379-388.

9. Sharma Y, Li B. 2010. The variation of power generation with organic substrates in single-chamber microbial fuel cells (SCMFCs). Bioresour. Technol. 101: 1844-1850.

10. Kacem SH, Galai S, De los Ríos AP, Fernández FJH, Smaali I. 2017. New efficient laccase immobilization strategy using ionic liquids for bio-catalysis and microbial fuel cells applications. J. Chem. Technol. Biotechnol. 93: 174-183.

11. Dwivedi UN, Singh P, Pandey VP, Kumar A, 2011. Review: structure-function relationship among bacterial, fungal and plant laccases. J. Mol. Catal. B: Enzymatic 68: 117-128.

12. Chaijak P, Sukkasem C, Lertworapreecha M, Boonsawang P, Wijasika S, Sato C. 2018. Enhancing electricity generation using a laccase-based microbial fuel cell with yeast Galactomyces reessii on the cathode. J. Microbiol. Biotechnol. 28: 1360-1366.

13. Barton SC, Pickard M, Vazquez-Duhalt R, Heller A. 2002. Electroreduction of O-2 to water at $0.6 \mathrm{~V}$ (SHE) at $\mathrm{pH} 7$ on the 'wired' Pleurotus ostreatus laccase cathode. Biosens. Bioelectron. 17: 1071-1074.

14. Mani P, Keshavarz T, Chandra TS, Kyazze G, 2017. Decolourisation of acid orange 7 in a microbial fuel cell 
with a laccase-based biocathode: influence of mitigating $\mathrm{pH}$ changes in the cathode chamber. Enzyme Microb. Technol. 96: 170-176.

15. Lai CY, Wu CH, Meng CT, Lin CW 2017. Decolorization of azo dye and generation of electricity by microbial fuel cell with laccase-producing white-rot fungus on cathode. Appl. Energy. 188: 392-398.

16. Johnson LF, Curl EA, JH Bond JH, HA. 1960. Fribourg, Methods for Studying Soil Mycoflora: Plant Diseases Relationships. pp. 179. Burgess Publishing Co., Minneapolis.

17. Moubasher AH. 1993. Soil Fungi in Qatar and other Arab Countries. pp. 566. The Scientific and Applied Research Centre., First ed. University of Qatar, Doha, Qatar.

18. Watanabe T. 2002. Soil and Seed Fungi. Pictorial Atlas of Soil and Seed Fungi. Morphologies of Cultured Fungi and Key to Species., Second ed. CRC Press. Boca Raton London New York Washington D.C.

19. Olga VKS, Elena VS, Valeria PG, Olga VM, Natalia VL, Aida ND, et al. 1998. Purification and characterization of the constitutive form of laccase from basidiomycete Coriolus hirsutus and effect of inducers on laccase synthesis. Biotechnol. Appl. Biochem. 28: 47-54.

20. Das P, Mukherjee S, Sen R. 2008. Improved bioavailability and biodegradation of a model poly aromatic hydrocarbon by a biosurfactant producing bacterium of marine origin. Chemosphere 72: 1229-1234.

21. (http://www.thermoscientificbio.com/)

22. Cheng $S$, Liu $H$, Logan $B, 2006$. Increased performance of single chamber microbial fuel cells using an improved cathode structure. Electrochem. Commun. 8: 489-494.

23. Khater DZ, El-Khatib KM, Hassan HM. 2017. Microbial diversity structure in acetate single chamber microbial fuel cell for electricity generation. J. Gen. Eng. Biotechnol. 15: 127-137.

24. Jadhav GS, Ghangrekar MM, 2009. Performance of microbial fuel cell subjected to variation in $\mathrm{pH}$, temperature, external load and substrate concentration. Bioresour. Technol. 100: 717-723.

25. Logan BE. 2008. Microbial Fuel Cells. pp. 216. First ed. New Jersey: John Wiley \& Sons.

26. https://www.energyavenue.com/LED-Light-Bulbs/Festoon/ 08-Watt.2019.

27. Brijwani K, Rigdon A, Vadlani PV. 2010. Fungal laccases: production, function, and applications in food processing. Enzyme Res. 2010: 149748.

28. Ghosh P, Ghosh U 2017. Statistical optimization of laccase production by Aspergillus flavus PUF5 through submerged fermentation using agro-waste as cheap substrate. Acta Biologica Szegediensis 61: 25-33.

29. Prajapati HV, Minocheherhomji FP. 2018. Laccase - a wonder molecule: a review of its properties and applications. Int. J. Pure Appl. Biosci. 6: 766-773.

30. Bhattacharya SS, Garlapati VK, Banerjee R. 2011. Optimization of laccase production using response surface methodology coupled with differential evolution. New Biotechnol. 28: 31-39.
31. Kirk PM, Cannon PF, Minter DW, Stalpers JA. 2008 Dictionary of the fungi. 10th ed. pp. 68. CABI, Wallingford, UK.

32. Cong B, Wang N, Liu S, Liu F, Yin X, Shen J, 2017. Isolation, characterization and transcriptome analysis of a novel Antarctic Aspergillus sydowii strain MS-19 as a potential lignocellulosic enzyme source. BMC Microbiol. 17: 129.

33. More SS, Renuka PS, Pruthvi K, Swetha M, Malini S, Veena SM. 2011. Isolation, purification, and characterization of fungal laccase from Pleurotus sp. Enzyme Res. 2011: 248735.

34. Pointing SB, Jones EBG, Vrijmoed LLP. 2000. Optimization of laccase production by Pycnoporus sanguineus in submerged liquid culture. Mycologia 92: 139-144

35. Hazuchová M, Chmelová D, Ondrejovič M, 2017. The optimization of propagation medium for the increase of laccase production by the white-rot fungus Pleurotus ostreatus. Nova Biotechnologica et Chimica 16: 113-123.

36. Vivekanand V, Dwivedi P, Pareek N, Singh RP. 2011. Banana peel: a potential substrate for laccase production by Aspergillus fumigatus VkJ2.4.5 in solid-state fermentation. Appl. Biochem. Biotechnol. 165: 204-220.

37. Minussi RC, Pastore GM, Duran N. 2002. Potential applications of laccase in the food industry. Trends Food Sci. Technol. 13: 205-216.

38. Couto R, Maria SS. 2005. Application of solid-state fermentation to ligninolytic enzyme production. Biochem. Eng. J. 36: 211-219 .

39. Pant D, Van Bogaert G, Diels L, Vanbroekhoven K, 2010. A review of the substrates used in microbial fuel cells (MFCs) for sustainable energy production. Bioresour. Technol. 101: 1533-1543.

40. Tanikkula P, Pisutpaisala N. 2015. Performance of a membrane-less air-cathode single chamber microbial fuel cell in electricity generation from distillery wastewater, Energy Procedia. 79: 646-650. Science Direct 2015 International Conference on Alternative Energy in Developing Countries and Emerging Economies.

41. Oh SE, Logan BE. 2005. Hydrogen and electricity production from a food processing wastewater using fermentation and microbial fuel cell technologies. Water Res. 39: 4673-4682.

42. Liu H, Cheng S, Logan BE. 2006. Production of electricity from acetate or butyrate using a single-chamber microbial fuel cell. Environ. Sci. Technol. 9: 658-662.

43. Flimban SGA, Ismail IMI, Kim T, Oh SE. 2019. Overview of recent advancements in the microbial fuel cell from fundamentals to applications: Design, major elements, and scalability. Energies 12: 3390.

44. Azuma M, Ojima Y. 2018. Catalyst Development of Microbial Fuel Cells for Renewable-Energy Production doi: 10.5772/ intechopen.81442. 